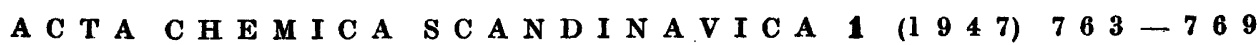

\title{
Equilibrium in Ammoniacal Solution of Silver Nitrate
}

\author{
REINO NÄSÄNEN
}

Propaedeutic-Chemical Laboratory of the University of Helsinki, Helsinki, Finland

W

hen silver ions are added to ammonia solution, the chief reaction is

$$
\mathrm{Ag}^{+}+2 \mathrm{NH}_{3}=\mathrm{Ag}\left(\mathrm{NH}_{3}\right)_{2}^{+}
$$

After this reaction is complete, further addition of silver nitrate results in the formation of a precipitate. The experiments and computation show, however, that when the stoichiometric concentration is chosen sufficiently small the precipitation does not yet begin at the inflection point of the titration curve. A homogeneous equilibrium therefore exists at the inflection point and it is thus possible to study quantitatively this equilibrium by determination of the maximum slope of the titration curve.

Application of the mass action law to the homogeneous equilibrium in ammoniacal solution of silver nitrate gives

$$
\begin{gathered}
{\left[\mathrm{Ag}^{+}\right]\left[\mathrm{NH}_{3}\right] /\left[\mathrm{AgNH}_{3}^{+}\right]=K_{1}} \\
{\left[\mathrm{AgNH}_{3}^{+}\right]\left[\mathrm{NH}_{3}\right] /\left[\mathrm{Ag}\left(\mathrm{NH}_{3}\right)_{2}^{+}\right]=K_{2}} \\
{\left[\mathrm{NH}_{4}^{+}\right][\mathrm{OH}] /\left[\mathrm{NH}_{3}\right]=K_{B}}
\end{gathered}
$$

According to Bjerrum ${ }^{1}$ complexes richer in ammonia than diammine are not present in analytically demonstrable quantities. In addition we have the stoichiometric equation

and

$$
c_{\mathrm{NH}_{3}}=\left[\mathrm{NH}_{3}\right]+\left[\mathrm{NH}_{4}^{+}\right]+\left[\mathrm{AgNH}_{3}^{+}\right]+2\left[\mathrm{Ag}\left(\mathrm{NH}_{3}\right)_{2}^{+}\right]
$$

$$
c_{\mathrm{Ag}}=\left[\mathrm{Ag}^{+}\right]+\left[\mathrm{AgNH}_{3}^{+}\right]+\left[\mathrm{Ag}\left(\mathrm{NH}_{3}\right)_{2}^{+}\right]
$$

where $c_{\mathrm{NH}_{3}}$ is the stoichiometric normality of ammonia and $c_{\mathrm{Ag}}$ that of silver nitrate $^{2}$. From electroneutrality of the solution it follows 


$$
c_{\mathrm{Ag}}+[\mathrm{O} \overline{\mathrm{H}}]=\left[\mathrm{Ag}^{+}\right]+\left[\mathrm{AgNH}_{3}^{+}\right]+\left[\mathrm{Ag}\left(\mathrm{NH}_{3}\right)_{2}^{+}\right]+\left[\mathrm{NH}_{4}^{+}\right]
$$

Introducing equation (6) into (7) the result is

$$
\left[\mathrm{NH}_{4}^{+}\right]=\left[\mathrm{OH}^{-}\right]
$$

From equations (4) and (8) we find that

$$
\left[\mathrm{NH}_{4}^{+}\right]=\sqrt{K_{B}}\left[\mathrm{NH}_{3}\right]^{\frac{1}{2}}
$$

Eliminating $\left[\mathrm{Ag}\left(\mathrm{NH}_{3}\right)_{2}^{+}\right]$between (5) and (6) gives

$$
c_{\mathrm{NH}_{3}}=2 c_{\mathrm{Ag}}-2\left[\mathrm{Ag}^{+}\right]+\left[\mathrm{NH}_{4}^{+}\right]-\left[\mathrm{AgNH}_{3}^{+}\right]+\left[\mathrm{NH}_{3}\right]
$$

By introducing equations (1) and (9) into (10) we find

$$
c_{\mathrm{NH}_{3}}{ }^{*}=2 c_{\mathrm{A}_{b}}-2\left[\mathrm{Ag}^{+}\right]+\sqrt{K_{B}}\left[\mathrm{NH}_{3}\right]^{\frac{1}{2}}+\left[\mathrm{NH}_{3}\right]-\left[\mathrm{Ag}^{+}\right]\left[\mathrm{NH}_{3}\right] / K_{1}
$$

If equation (2) and (3) are solved for $\left[\mathrm{AgNH}_{3}^{+}\right]$and $\left[\mathrm{Ag}\left(\mathrm{NH}_{3}\right)_{2}^{+}\right]$as well as substituted in equation (6) there results

$$
c_{\mathrm{Ag}}=\left[\mathrm{Ag}^{+}\right]+\frac{\left[\mathrm{Ag}^{+}\right]}{K_{1}}\left[\mathrm{NH}_{3}\right]+\frac{\left[\mathrm{Ag}^{+}\right]}{K_{1} K_{2}}\left[\mathrm{NH}_{3}\right]^{2}
$$

Solving with respect to $\left[\mathrm{NH}_{3}\right]$ yields

or

$$
\left[\mathrm{NH}_{3}\right]=-K_{2} / 2+\sqrt{K_{2}^{2} / 4-K_{1} K_{2}+K_{1} K_{2} c_{\mathrm{Ag}} /\left[\mathrm{Ag}^{+}\right]}
$$

in which

$$
\left[\mathrm{NH}_{3}\right]=A x^{-\frac{1}{2}}(1-\delta)^{\frac{1}{2}}-K_{2} / 2
$$

$$
A=\sqrt{K_{1} K_{2} c_{\mathrm{Ag}}}, \quad x=\left[\mathrm{Ag}^{+}\right] \text {and } \delta=\left(1-K_{2} / 4 K_{1}\right) x / c_{\mathrm{Ag}}
$$

Approximative expression for $\left[\mathrm{NH}_{3}\right]$ are

and

$$
\left[\mathrm{NH}_{3}\right]=A x^{-\frac{1}{2}}(1-\delta)^{\frac{1}{2}}
$$

$$
\left[\mathrm{NH}_{3}\right]=A x^{-\frac{1}{2}}
$$

Introducing expression (14) into equation (11) gives

$$
\begin{gathered}
c_{\mathrm{NH}_{3}}=2 c_{\mathrm{Ag}}-K_{2} / 2-2\left(1-K_{2} / 4 K_{1}\right) x+A x^{-\frac{1}{2}}(1-\delta)^{\frac{1}{2}}-A^{\prime} x^{\frac{1}{2}}(1-\delta)^{\frac{1}{2}} \\
+B x^{-\frac{1}{4}}(1-\delta)^{\frac{1}{4}}
\end{gathered}
$$


in which

$$
A^{\prime}=A / K_{1} \text { and } B=\sqrt{A K_{B}}
$$

The term $B x^{-\frac{1}{4}}(1-\delta)^{\frac{1}{4}}$ is obtained using the approximative expression (16). This term is namely small as compared with other terms and the error made is therefore negligible. Differentiating (18) with respect to $p x=-\log x$ yields

$$
\begin{gathered}
P=2.303\left\{2\left(1-K_{2} / 4 K_{1}\right) x+1 / 2 A x^{-\frac{1}{2}}(1-\delta)^{-\frac{1}{2}}+1 / 2 A^{\prime} x^{\frac{1}{2}}(1-\delta)^{-\frac{1}{2}}(1-2 \delta)+\right. \\
\left.+1 / 4 B x^{-\frac{1}{4}}(1-\delta)^{-\frac{3}{4}}\right\}
\end{gathered}
$$

Equation (20) is valid by titration with ammonia solution at which $c_{\mathrm{Ag}}$ remains constant. By titration with silver nitrate solution the case becomes more complicated. This is not dealt with in this paper. Some titrations carried out in this manner, however, give the same value for the constant $K_{1} K_{2}$ as the titrations performed in the reverse direction. Differentiating once more with respect to $p x$ and equating to zero gives after rearranging

$$
x=\left(1 / 8 A F_{1}-1 / 8 A^{\prime} x F_{2}+1 / 32 B x^{-\frac{1}{4}} F_{3}\right)^{\frac{2}{3}}\left(1-K_{2} / 4 K_{1}\right)^{-\frac{2}{3}}
$$

in which

$$
\begin{gathered}
F_{1}=(1-2 \delta)(1-\delta)^{-\frac{3}{2}} \\
F_{2}=\left(1-6 \delta+4 \delta^{2}\right)(1-\delta)^{-\frac{3}{2}} \\
F_{3}=(1-4 \delta)(1-\delta)^{-\frac{7}{4}}
\end{gathered}
$$

From equation (21) the silver ion concentration at inflection point can be calculated. With the aid of the experimental value of the quantity $P$ at the inflection point and the values of $K_{1}, K_{B}$ and $c_{\mathrm{Ag}}$ the constant $K_{1} K_{2}$ can be computed from equations (20) and (21). It is then convenient to use equation (20) in the form

$$
A=\left\{0.434 P-2\left(1-K_{2} / 4 K_{1}\right) x-1 / 4 B x^{-\frac{1}{4}}(1-\delta)^{-\frac{3}{4}}\right\} \frac{2 x^{\frac{1}{2}}(1-\delta)^{\frac{1}{2}}}{1+x / 4 K_{1}(1-2 \delta)}
$$

For computations the constant $K_{1}$ is obtained according to Bjerrum ${ }^{1}$ from

$$
\mathrm{p} K_{1}=3.315-0.01 \mu
$$

and $K_{B}$ according to Kilpi ${ }^{3}$ from

$$
\mathrm{p} K_{B}=4.733-\frac{V \bar{\mu}}{1+1.8 \sqrt{\mu}}+0.036 \mu
$$


If approximative equation (16) or (17) is introduced into equation (11) equations are obtained which follow also from (18), (20) and (21) by substituting $K_{1} / 4 K_{2}=0$ in the first case and in addition $\delta=0$ in the latter case. By using these equations we obtain a value for $\mathrm{p} K_{1} K_{2}$ which is in the first case about 0.02 and in the latter case about 0.035 smaller than that obtained with the aid of equations (21) and (25).

\section{EXPERIMENTAL}

The titrations were performed in a water thermostat at $25 \pm 0.01^{\circ}$. As indicator electrode a silver iodide electrode was used. Tank nitrogen, carbon dioxide free, was bubbled through solution. The titration vessel employed was similar to that used earlier 4. The $\mathrm{K}$ type potentiometer of Leeds \& Northrup was used for measurement of the electromotive force.

Kahlbaum's chemicals for analysis were used. Carbonate-free ammonia solution was prepared by passing ammonia gas, obtained by heating strong ammonia water containing a little calcium hydroxide, into water.

For further experimental details, especially for the calculation of the minimum value of the quantity $P$ from potentiometric data, the reader is referred to the earlier papers of the author 4

\section{RESULTS}

A separate titration was carried out as follows. First $50 \mathrm{ml}$ water or potassium nitrate solution and the main part of the $0.305 \mathrm{~N}$ ammonia solution were added in the titration vessel. Now during vigorous stirring $5 \mathrm{ml}$ of $0.05 \mathrm{~N}$ silver nitrate was slowly dropped in. When the potential of the indicator electrode became constant, the fine titration for determination of the maximum slope of the titration curve was performed with the above $0.305 \mathrm{~N}$ ammonia solution. The data of a typical tiration are given in Table 1, where the denotations are:

$C_{\mathrm{NH}_{3}}$ and $C_{\mathrm{Ag}}$ respectively, the normality of ammonia solution and of silver nitrate solution respectively,

$a_{\mathrm{NH}_{3}}$ and $a_{\mathrm{Ag}}$ respectively, the amount of the ammonia and of the silver nitrate solution respectively, added up to the inflection point in $\mathrm{ml}$,

$\Delta a$ the mean increment of ammonia solution in $\mathrm{ml}$,

$\Delta E$ the maximum jump of the potential as interpolated from the e.m.f. values in $\mathrm{mV}$,

$V$ the volume of the titrated solution at the inflection point in $\mathrm{ml}$,

$\boldsymbol{P}$ the reciprocal value of the maximum slope of the titration curve. 
Table 1. A typical titration of silver nitrate solution with ammonia solution.

\begin{tabular}{|r|c|c|c|}
\hline$t$ & $a$ & $E$ & $\Delta E$ \\
\hline 0 & 1.501 & 270.8 & \\
6 & 1.607 & 261.4 & 9.4 \\
12 & 1.713 & 250.7 & 10.7 \\
18 & 1.819 & 239.0 & 11.7 \\
24 & 1.925 & 227.5 & 11.5 \\
30 & 2.031 & 217.2 & 10.3 \\
\hline
\end{tabular}

$$
\begin{aligned}
& C_{\mathrm{NH}_{3}}=0.305 . C_{\mathrm{Ag}}=0.0500 \\
& a_{\mathrm{NH}_{3}}=1.801 . a_{\mathrm{Ag}}=5.00 . \\
& c_{\mathrm{NH}_{3}}=9.69 \cdot 10^{-3} \cdot c_{\mathrm{Ag}}=4.40 \cdot 10^{-3} \\
& c_{\mathrm{NH}_{3}}-2 c_{\mathrm{Ag}}=\left\{\begin{array}{l}
0.89 \cdot 10^{-3} \text { (found) } \\
0.91 \cdot 10^{-3} \text { (calc) }
\end{array}\right. \\
& \Delta a=0.106 . \Delta E=11.81 . \mathrm{V}=56.8 . P=2.85 \cdot 10^{-3} .
\end{aligned}
$$

Table 2 includes the data of the titrations, some of which are carried out with added potassium nitrate. Silver nitrate concentration is the same in all titrations. The numerical values of the constant $K_{1} K_{2}$, the ion concentrations at inflection point calculated from the data of Table 2 as well as the corresponding values of the constants $K_{1}$ and $K_{B}$ are given in Tables 3 and 4. From Tables 3 and 4 it appears that the constant $K_{1} K_{2}$ is within the limit of experimental errors independent of ionic strength. For this constant at the ionic strength zero is thus obtained

$$
\mathrm{p} K_{1}^{\circ} K_{2}^{\circ}=7.21
$$

which is the average value of the values in Tables 3 and 4.

Table 2. Computation of maximum slope of the titration curve from potentiometric data.

\begin{tabular}{|c|c|c|c|c|c|c|c|c|}
\hline$\mu$ & $V$ & $\Delta a$ & $\Delta E$ & $P \cdot 10^{3}$ & $c_{\mathrm{Ag}} \cdot 10^{3}$ & $c_{\mathrm{NH}_{3}} \cdot 10^{3}$ & \multicolumn{2}{|c|}{$\left(c_{\mathrm{NH}_{3}}-2 c_{\mathrm{Ag}}\right) \cdot 10^{3}$} \\
& & & & & & & found & calc. \\
\hline & & & & & & & & \\
0.0044 & 56.81 & 0.106 & 11.83 & 2.84 & 4.40 & 9.73 & 0.93 & 0.82 \\
0.0044 & 56.79 & 0.107 & 12.07 & 2.80 & 4.40 & 9.61 & 0.81 & 0.82 \\
0.0044 & 56.80 & 0.106 & 12.15 & 2.77 & 4.40 & 9.69 & 0.89 & 0.82 \\
0.0044 & 56.80 & 0.104 & 11.80 & 2.79 & 4.40 & 9.68 & 0.88 & 0.82 \\
1.00 & 56.75 & 0.106 & 12.20 & 2.76 & 4.40 & 9.70 & 0.90 & 0.85 \\
1.00 & 56.81 & 0.107 & 12.05 & 2.82 & 4.40 & 9.65 & 0.85 & 0.85 \\
1.00 & 56.82 & 0.105 & 11.90 & 2.80 & 4.40 & 9.64 & 0.84 & 0.85 \\
1.00 & 56.79 & 0.106 & 12.10 & 2.78 & 4.40 & 9.67 & 0.87 & 0.85 \\
\hline
\end{tabular}


Table 3. Equilibrium constants and ion concentrations at inflection point when $\mu=0.0044$ and $P=2.80 \cdot 10^{3}$.

$\begin{array}{llllll}K_{1} & 4.85 \cdot 10^{-4} & {\left[\mathrm{Ag}^{+}\right]} & 1.42 \cdot 10^{-4} & {\left[\mathrm{OH}^{-}\right]} & 1.67 \cdot 10^{-4} \\ K_{B} & 2.12 \cdot 10^{-5} & {[\mathrm{AgNH}} & + \\ K_{1} K_{2} & 6.26 \cdot 10^{-8} & {\left[\mathrm{Ag}\left(\mathrm{NH}_{3}\right)_{2}^{+}\right] 3.90 \cdot 10^{-4}} & {\left[\mathrm{NH}_{4}^{+}\right]} & 1.67 \cdot 10^{-4} \\ & & & {\left[\mathrm{NH}_{3}^{-3}\right]} & 1.31 \cdot 10^{-3}\end{array}$

Table 4. Equilibrium constants and ion concentrations at inflection point when $\mu=1.00$ and $P=2.79 \cdot 10^{-3}$.

$\begin{array}{llllll}K_{1} & 4.95 \cdot 10^{-4} & {\left[\mathrm{Ag}^{+}\right]} & 1.43 \cdot 10^{-4} & {\left[\mathrm{OH}^{-}\right]} & 2.14 \cdot 10^{-4} \\ K_{B} & 3.87 \cdot 10^{-5} & \left.[\mathrm{AgNH})_{3}^{+}\right] & 3.76 \cdot 10^{-4} & {\left[\mathrm{NH}_{4}^{+}\right]} & 2.14 \cdot 10^{-4} \\ K_{1} K_{2} & 6.20 \cdot 10^{-8} & {\left[\mathrm{Ag}\left(\mathrm{NH}_{3}\right)_{2}^{+}\right]} & 3.91 \cdot 10^{-3} & {\left[\mathrm{NH}_{3}\right]} & 1.30 \cdot 10^{-3}\end{array}$

\section{DISCUSSION}

From the values of Table 3 it follows that the product $\left[\mathrm{Ag}^{+}\right]\left[\mathrm{OH}^{-}\right]=$ $2.37 \cdot 10^{-8}$ at inflection point when $\mu=0.0044$. In this ionic strength the solubility product of silver oxide has the value $3.13 \cdot 10^{-8}$ according to the measurements by the present author ${ }^{5}$. As regards Table $4\left[\mathrm{Ag}^{+}\right][\mathrm{OH}]=3.06 \cdot 10^{-8}$ and the solubility product is $8.26 \cdot 10^{-8}$. Thus the equilibrium in both cases is homogeneous, even if in the first instance the beginning of precipitation is near.

Inflection point and equivalent point differ from each other. According to calculations and measurements the difference $c_{\mathrm{NH}_{3}}-2 c_{\mathrm{Ag}}$ is about $1 \cdot 10^{-3}$. The silver ion concentration at equivalent point can be calculated according to equation (18), from which we obtain after substituting $c_{\mathrm{NH}_{3}}=2 c_{\mathrm{Ag}}$ and rearranging

$$
\left[\mathrm{Ag}^{+}\right]=\left\{\frac{A(1-\delta)^{\frac{1}{2}}-A^{\prime} x(1-\delta)^{\frac{1}{2}}+B x(1-\delta)^{\frac{1}{2}}-K_{2} / 2 x^{\frac{1}{2}}}{2\left(1-K_{2} / 4 K_{1}\right)}\right\}^{\frac{2}{3}}
$$

The corresponding value of $\left[\mathrm{OH}^{-}\right]$can be calculated from equations (13) and (9) when equation (8) is taken into account. In the above experimentally studied cases we obtain for $\left[\mathrm{Ag}^{+}\right],[\mathrm{OH}]$ and $\left[\mathrm{Ag}^{+}\right][\mathrm{OH}]$ the following values at equivalent point

\begin{tabular}{|c|c|c|c|}
\hline$\mu$ & {$\left[\mathrm{Ag}^{+}\right]$} & {$[\mathrm{OH}]$} & {$\left[\mathrm{Ag}^{+}\right][\mathrm{O} \overline{\mathrm{H}}]$} \\
\hline 0.0044 & $2.75 \cdot 10^{-4}$ & $1.40 \cdot 10^{-4}$ & $3.85 \cdot 10^{-8}$ \\
1.00 & $2.83 \cdot 10^{-4}$ & $1.86 \cdot 10^{-4}$ & $5.32 \cdot 10^{-8}$ \\
\hline
\end{tabular}


In the first case the product $\left[\mathrm{Ag}^{+}\right][\mathrm{OH}]$ is thus greater than the solubility product. No precipitation at equivalent point is, however, observed. In pAg units the difference between inflection and equivalent point is in both cases about 0.3 . The corresponding $\mathrm{pH}$ difference is about $\mathbf{0 . 0 7}$. Thus the potential jump of the silver electrode is about four times greater than the corresponding potential jump of the glass electrode. This state of things follows also from the approximative equation

$$
[\mathrm{OH}]=B\left[\mathrm{Ag}^{+}\right]^{-\frac{1}{4}}
$$

which is obtained from (8), (9) and (17).

When the concentration of $\mathrm{AgNH}_{3}^{+}$is not taken into consideration, we obtain for $\mathrm{p} K_{1} K_{2}$ a value which is 0.2 smaller than the value calculated above.

The value $\mathrm{p} K_{1}^{\circ} K_{2}^{\circ}=7.21$ obtained in the present paper is in good agreement with the values in the literature, especially with the value $\mathrm{p} K_{1}^{\circ} K_{2}^{\circ}=$ 7.23 obtained by Bjerrum ${ }^{1}$.

\section{SUMMARY}

Equilibrium in ammoniacal silver nitrate solution is studied potentiometrically. At the inflection point which occurs when one mole silver nitrate per two moles ammonia is added, the equilibrium is homogeneous, if the solution is sufficiently dilute.

The maximum slope of the titration curve is determined and the equilibrium constant is calculated from experimental values. The values obtained agree satisfactorily with the previous values in the literature.

The influence of potassium nitrate additions on the equilibrium constant lies within the limit of experimental errors.

\section{REFERENCES}

1. Bjerrum, J. Doctoral Thesis. Copenhagen (1941) p. 130.

2. Hydroxo compounds are formed only in negligible amounts. $C f$. Laue, E. $Z$. anorg. Chem. 165 (1927) 325; Britton, H. T. S., and co-workers, J. Chem. Soc. (1933) 1050; Ibid. (1935) 796; Ibid. (1936) 96.

3. Kilpi, S. Z. phys. Chem. (A) 180 (1937) 464.

4. Näsänen, R. Z. physik. Chem. (A) 188 (1941) 272; (A) 190 (1942) 183; (A) 191 (1942) 54; Suomen Kemistilehti 16B (1943) 1; 17B (1944) 11; 18B (1945) 45. 